\title{
АНАЛИЗ ГЕНДЕРНЫХ ПРОБЛЕМ ПРИ БЕСПЛОДИИ В СУПРУЖЕСТВЕ
}

\author{
Основа взаимоотношений мужчины и женщины - \\ естественное стремление к продолжению человеческого \\ рода. Рождение и воспитание ребенка в любом обществе \\ воспринимаются как ступень к достижению зрелости \\ и сексуального самоутверждения, реальных положительных \\ перспектив
}

\section{Е.Н. БОРИС \\ к.мед.н., доцент кафедры акушерства, гинекологии и репродуктологии НМАПО им. П.Л.Шупика, директор Центра научно-доказательной медицины, главный репродукто- лог ГУЗО г.Киева}

\section{О.В. РОМАЩЕНКО}

д.мед.н., главный научный сотрудник отдела сексопатологии и андрологии Института урологии НАМН Украины

\section{М.В. ПОВОРОЗНЮК}

врач сексопатолог-андролог НМАПО им. П.Л.Шупика

И.Б. БилоголОвСКИй врач Институт урологии НАМН Украины

\section{М.Г. ТЮНИНА}

психотерапевт Институт урологии НАМН Украины
$\mathrm{O}$ днако, по данным ВОЗ, во многих странах мира сохраняется тенденция к увеличению числа супружеских пар, страдающих бесплодием (8-10\% в популяции) [1].

Одна из причин явного роста бесплодных пар связана с улучшением методов диагностики и активным внедрением в практическую медицину вспомогательных репродуктивных технологий (ВРТ) [2]. Необходимо учитывать также и тот фракт, что благодаря созданию и совершенствованию за последние 30-40 лет системы планирования семьи для женщин открыт доступ к современным контрацептивным средствам, позволяющим контролировать фертильность и возможность перенести беременность на более поздний возрастной период.

Бесплодие в супружестве условно обозначается как биографический раскол, ибо это определение позволяет в некоторой степени отразить страдания и эмоциональные конфликты тех, кто находится в таком состоянии. Частичная или полная утрата возможности рождения желанного ребенка становится моральной потерей в жизни пар, отождествляемой с потерей близкого человека [3].

Согласно данным P. Lauritzen, при мужском бесплодии у пациентов преобладают чувства, сравнимые с потерей ребенка, которого они надеялись иметь в реальном будущем [4].

В последние десятилетия, когда знание и понимание репродуктивной фризиологии расширили горизонты медицины, в практику вошли новые ВРТ, способствующие созданию терапевтических альтернатив при лечении семейного бесплодия. На наш взгляд, внедрение в практическую медицину новых технологий, способствующих рождению ребенка, должны быть исследованы в более широком контексте, включающем социальные, экономические, исторические, культурные категории. В то же время понимание истинного значения проблемы бес- плодия в личностном аспекте как для женщины, так и для мужчины, возможно только с учетом их гендерных ролей.

Термин «гендер» происходит от латинского слова genus - пол. Первоначально его использовали с целью отличия полов в анатомическом, а не в социальном или психологическом смысле. Пол определяет анатомическую организацию различий между мужчиной и женщиной, в то время как гендер указывает на социальные и психологические особенности сексуальной личности. В широком смысле гендер является социальным определением, характеризующим социальные взаимоотношения полов, а также роли, которые мужчина и женщина выполняют в обществе [5].

По мнению V. Matamala и O. Maynou, в основе этого определения содержатся четыре основных принципа, которые и обозначают социальные взаимоотношения между мужчиной и женщиной: сексуальность, репродуктивная активность, сексуальное разделение по роду профессиональной занятости, распределение в обществе в зависимости от гражданской позиции [6].

В основе гендера лежит различие по степени влияния в обществе и положения в этом обществе женщины и мужчины. В начале 70-х годов XX в., когда вопрос гендерных ролей и прав женщин стал одной из основных проблем общества, появились и широко распространились новые современные контрацептивы, в том числе гормональные, которые использовали преимущественно женщины, получив дополнительную степень свободы. Доступ к современным методам контрацепции позволил женщинам свободно планировать рождение желанного ребенка или откладывать беременность в силу разных причин на более позднее время. Возможность женщины принимать независимое решение о времени желанной беременности увеличила значимость ее роли в решении столь важного в семье вопроса - рождении ребенка. 
Несмотря на современные достижения в области репродуктологии, все в этом мире возвращается на круги своя: основным предназначением женщины в обществе по-прежнему остается способность производить на свет детей. В связи с этим женщин условно распределяют на репродуктивно активных и неспособных к реализации репродуктивной функции.

В то же время такое определение как «безотцовщина» в социальном смысле давно не существует. Понятие материнства символизирует тесную взаимосвязь матери и ребенка не только в биологическом смысле. Мужчины в большинстве своем определяют отношение к ребенку по степени понимания принципов отцовства, которые связаны с правом собственности на детей, так как новорожденный происходит из их спермы.

До 50-х годов прошлого века большинство исследований по изучению бесплодия были сосредоточены на психосоциальных, а не биологических причинах данной проблемы. На протяжении последующих двадцати лет с развитием диагностических технологий и лапароскопии исследовались более глубоко женские и мужские анатомические, патофизиологические, инфекционные, морфологические, иммунные, эндокринные и прочие причины бесплодия. С помощью новых технологий стало возможно более точно установить биологические причины бесплодия, которые ранее не учитывались. Лучшее знание репродуктивной эндокринологии позволило с большей степенью точности вмешиваться в нарушения различных генеративных функций мужского и женского организмов, чтобы реабилитировать столь важные фризиологические процессы.

Несмотря на то, что научный прогресс позволяет разрушить традиционные гендерные роли в структуре семьи, он не смог до конца разрушить социальные нормы гендерных отношений в семье [7]

Несомненно, женщины и мужчины, страдающие бесплодием, испытывают дискомфорт в обществе, в котором преобладают семьи с сохраненной способностью иметь детей. Желание иметь ребенка является главенствующим в каждой семье. Быть родителями - необходимая часть естественной жизни совершеннолетних мужчин и женщин. В связи с этим последствия бесплодия, которые по-разному в эмоциональном плане влияют на мужчину и женщину, должны быть более глубоко изучены, объяснены и учтены.

Когда ожидаемые надежды при создании той или иной модели семьи не оправданы, партнеры, каждый в отдельности или одновременно, должны пройти определенный процесс психологических перемен, чтобы адаптироваться к неожиданной реальности. При бесплодии в супружестве, традиционно обвиняя женщи- ну, мужчина подсознательно упрекает ее за последствия возможных ранее сексуальных контактов. Вот почему чаще всего женщины первыми обращаются за специализированной медицинской помощью, проходят диагностические процедуры. В последнее время такая позиция пересмотрена, и концепция одновременного обследования супругов при бесплодии стала доминирующей.

ВРТ расширили возможность реабилитации репродуктивной функции мужчин и женщин, но не изменили дисбаланс их участия в необходимом лечении. По сей день большая степень ответственности и проблем возлагается на женщину. Поскольку ВРТ базируются на различных вмешательствах в фертильную активность женского организма, они укрепляют фракт материнства в биологическом, а не социальном значении.

C. Crowe утверждает, что женщины считают материнство более важным, чем передача генетической инфрормации при биологическом материнстве [8].

Социально-психологические последствия для бесплодных пар возросли при развитии ВРТ, которые стали своеобразной «репродуктивной пулей», позволяющей эффрективно решать репродуктивные вопросы. Неудачи в использовании таких технологий приводят к большим психоэмоциональным последствиям, порой даже более глубоким, чем их недоступность. В некоторых случаях фертильные пары могут использовать следующий методики:

искусственную инсеминацию фертильной женщине при мужском факторе (олиго-, аспермия и пр.) либо при иммунологическом бесплодии;

(2) предимплантационную генетическую диагностику при наличии риска генетической патологии плода, которая позволяет провести генетическое тестирование эмбриона до переноса его в полость матки;

анатомический мужской фрактор при сохраненной фертильности мужчины (например врожденные дефекты половых органов, травмы, осложнения после хирургических операций обструкция семявыносящего протока и пр.);

(3) суррогатное материнство при экстрагенитальной патологии матери, несовместимой с беременностью и/или родами;

д донацию биологического материала (яйцеклетки, сперматозоида, эмбриона) при наличии соматических, генетических рисков у родителей [9].

Существующий дисбаланс между уровнями возможных потребностей в лечении супружеского бесплодия и разработанных ВРТ заключается в первую очередь в том, что при решении проблемы не учитываются психоэмоциональные аспекты каждого из супругов, и несоблюдение этих деталей приводит к гендерному дисбалансу.

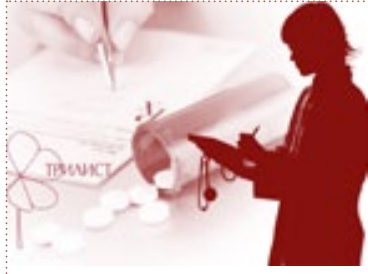

Социально-психологические последствия для бесплодных пар возросли при развитии вспомогательных репродуктивных технологий, которые стали своеобразной «репродуктивной пулей», позволяющей эффективно решать репродуктивные вопросы. Неудачи в использовании таких технологий ведут к большим психоэмоциональным последствиям, порой более глубоким, чем их недоступность. Эти методики в некоторых случаях могут использоваться также фертильными парами:

5 искусственная инсеминация фертильной женщине при мужском факторе (олигоаспермия и пр.), либо при иммунологическом бесплодии;

(3) предимплантационная генетическая диагностика при наличии риска генетической патологии плода, которая по зволяет провести генетическое тестирование эмбриона еще до переноса его в полость матки;

ร анатомический мужской фактор при сохраненной фертильности мужчины (например, врожденные дефекты половых органов, травмы, осложнения после хирургических операций обструкция семявыносящего протока и пр.)

(3) суррогатное материнство при экстрагенитальной патологии матери, не совместимой с беременностью и/или родами;

s. донация биологического материала (яйцеклетки, спермато зоида, эмбриона) при наличии соматических, генетических рисков у родителей и пр. 


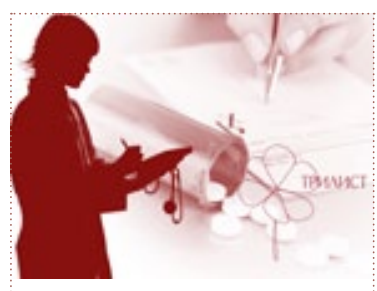

Проблема бесплодия в супружестве должна рассматриваться с учетом биологических психоэмоциональных, соци альных и гендерных соотношений. Выбор тактики лечения в каждом конкретном случае должен быть аргументирован в зависимости от характера и степени изменений со сторонь органов репродуктивной системы мужчины и женщины и адаптирован к их психоэмоциональному состоянию. При лечении бесплодия в супружестве методологические подходы и выбор тактики терапии гинеко логу необходимо обосновывать совместно с андрологом и психотерапевтом. Обследование и лечение супругов при семейном бесплодии должно проводиться одновременно
Учитывая важность представленных задач, мы поставили цель изучить спектр гендерных проблем при бесплодии в супружестве.

Нами обследовано 152 супружеские пары, страдающие бесплодием от 2 до 12 лет (исследование проводилось на кафедре акушерства, гинекологии и репродуктологии УГИР НМАПО имени П.Л.Шупика и на базе Институт урологии НАМН Украины). Среди них первичное бесплодие имели 72 пары (47,4\%), вторичное - 80 (52,6\%). Женский фрактор бесплодия преобладал у 112 (73,7\%) обследованных пар, мужской - у 40 (26,3\%). Изучение анамнеза показало, что консервативное лечение назначали всем участникам исследования, реконструктивные хирургические операции с целью восстановления проходимости маточных труб - 29 (19,1\%) женщинам, искусственную инсеминацию - 28 $(18,4 \%)$, экстракорпоральное оплодотворение от одного до трех раз - 12 (7,9\%).

В начале исследования проводили собеседование с каждым из супругов в отдельности, оценивая отношение их как к проблеме бесплодия, так и к необходимому лечению. Анализ полученной инфоомации показал, что у мужчин и женщин бесплодие в супружестве сопряжено с глубокими эмоциональными переживаниями, порой обозначаемыми как состояние безвыходности и безнадежности в будущем. В 128 (84,2\%) случаях женщины испытывали большее угнетение, чем мужчины, мужья в 31 (20,4\%) случае переживали преимущественно за свое будущее, в 48 (31,6\%) - за своих жен, остальные 73 (48,1\%) мужчины реально и спокойно воспринимали действительность.

В 48 (31,6\%) случаях оба пола использовали стратегию активного продолжения лечения и расценивали такую тактику как возможность решить проблему. У 34 (22,4\%) пар с каждым новым курсом терапии нарастали недоверие к выбору метода лечения и ощущения бесперспективности его результатов. Наибольший стресс испытывали женщины после неудавшихся попыток экстракорпорального оплодотворения. В 62 (40,8\%) случаях мужчины с пониманием относились к переживаниям жен, поскольку осознавали, что большую часть испытаний как эмоциональных, так и физических испытывают именно они.

Анализ результатов опроса мужчин и женщин показал, что бесплодие в супружестве приводит к брачному конфлликту, глубина которого зависит от степени стресса во время лечения. В 29 (19,1\%) случаев совместное решение проблемы бесплодия в семье способствовало сближению супругов: отношения между ними становились эмоционально глубже и интимнее. Мужчиныконцентрировалисвоисилынадостижении соответствующих целей в обществе, женщи ны-на особенностях межличностных отношений.
У 19 (12,5\%) пар, страдающих бесплодием, отношения в семьях сохранились ровными, они расценивали такой вариант семьи комфортным.

Женщины во всех случаях обращались за психологической помощью, поддержкой, мужчины же это делали в исключительных случаях; в нашем исследовании в 139 (91,4\%) случаях замыкались в себе. Жены находили утешение у мужей значительно чаще, чем мужья у жен.

Таким образом, проведенные исследования доказали, что проблема бесплодия в супружестве должна рассматриваться с учетом биологических, психоэмоциональных, социальных и гендерных отношений. Выбор тактики лечения в каждом случае необходимо аргументировать в зависимости от характера и степени изменений со стороны органов репродуктивной системы мужчины и женщины и адаптировать к их психоэмоциональному состоянию. При лечении бесплодия у супругов гинекологу нужно обосновывать методологические подходы и выбор тактики терапии совместно с андрологом и психотерапевтом. При семейном бесплодии обследование и лечение супругов должно проводиться одновременно.

\section{ЛИТЕРАТУРА}

1. Connoly $\mathrm{K}$.

The impact of infertility on psychological functioning // Journal of Psychosomatic Research. - 1992. - № 36. - P. 459-468.

2. Rowland R.

Women and reproductive technologies // Blomington, Indiana University Press. - 1992

3. Daniels K.

Management of the psychosocial aspects of infertility // Australia and New Zeland Journal of Obstetrics and Gynecology. - 1992. - №32. P. 57-61.

4. Lauritzen $P$.

Pursuing parenthood. Ehtical issues in assisted reproduction // Bloomington, Indiana University Press. - 1993

5. Natchingall R.D., Becker G., Wozny M.

The effects of gender-specific diagnosis on men's and women's response to infertility // Fertility and Strility. - 1992. - № 57. - P. 113-121.

6. Matamala V.M.I., Maynou O.P.

Salud de la mujer. Calidad de la atencion y genero. Manual guia para la realization del Curso-Taller Salud y Medecina Social. Santiago, Ediciones LOM Lta. - 1996.

\section{Guerra D. et al.}

Psychiatric morbidity in couples attending fertility service // Human Reproduction. - 1998. - № 13. - P. 1733-1736.

8. Crowe $\mathrm{C}$

Women want it: in vitro fertilization and woman's motivations for participation / In: Spallone P, Steinberg DL, eds. Made to order. The myth of reproductive and genetic progress. Elmsford, NY, Pergamon Press. - 1987.

9. Savulesco J., Dahl E.

Sex selection and preimplantation diagnosis: a response to the Ethics Committee of the American society of Reproductive Medicine // Human reproduction. - 2000. - № 15. - P. 1879-1880. 